\title{
Desirability and Design of Experiments Applied to the Optimization of the Reduction of Decarburization of the Process Heat Treatment for Steel Wire Sae 51B35
}

\author{
Cristie Diego Pimenta ${ }^{1}$, Messias Borges Silva ${ }^{2}$, Rose Lima de Morais Campos ${ }^{3}$, \\ Walfredo Ribeiro de Campos Junior ${ }^{4}$ \\ ${ }^{1}$ Department of Business, Dehoniana College, São Paulo, Brazil \\ ${ }^{2}$ Department of Production, University of Guaratinguetá (Feg-Unesp), São Paulo, Brazil \\ ${ }^{3}$ Department of Business, ITES College, São Paulo, Brazil \\ ${ }^{4}$ Department of Marketing, College ESPM, São Paulo, Brazil
}

Email address:

pimentadiego@yahoo.com.br (C. D. Pimenta), messias.silva@feg.unesp.br (M. B. Silva), campos_rose@ig.com.br (R. L.de M. Campos), wrcampos@gmail.com (W. R. de C. Junior)

\section{To cite this article:}

Cristie Diego Pimenta, Messias Borges Silva, Rose Lima de Morais Campos, Walfredo Ribeiro de Campos Junior. Desirability and Design of Experiments Applied to the Optimization of the Reduction of Decarburization of the Process Heat Treatment for Steel Wire Sae 51 B35. American Journal of Theoretical and Applied Statistics. Vol. 7, No. 1, 2018, pp. 35-44. doi: 10.11648/j.ajtas.20180701.15

Received: December 26, 2017; Accepted: January 10, 2018; Published: January 23, 2018

\begin{abstract}
This study contributes directly to the understanding of the causative agent of loss of carbon steel wire during the heat treatment (phenomenon called decarburization). This carbon loss disqualifies the material for your applications originally envisaged, as with mechanical reduction of the amount of the chemical element carbon steel becomes less resistant to traction and less hard what would prevent your use for various applications mechanics. This research aim is to show desirability method application related to decarburization and hardness, in SAE 51B35 drawn steel wires. Data were generated from application of design of experiments methodology (by means of the Minitab Statistical Software) and results revealed that all variables considered in study have significant influence. Statistic modeling was carried out by means of application of multiple linear regression method which allowed obtaining models which represent properly the process itself. Results of response variables decarburization and hardness were submitted to desirability method application and the process was optimized at the best adjust condition of entry variables in relation to their specifications.
\end{abstract}

Keywords: Design of Experiments, Multiple Linear Regression, Desirability Function

\section{Introduction}

The practice of applications of statistical methods is now in your time of greatest use. In manufacturing, process industries, hospitals and services, statistical thinking is being used to decrease costs, reduce defects and control the variability.

Contrary to popular belief, usually the statistic is not just data analysis, she is also planning of experiments in which those data are collected. Maybe we should even say she is mainly for more sophisticated planning that is the analysis that then, the lack of planning is often the cause of failure of an investigation, and yet very few researchers who think in statistics before perform your experiments.
This work used design of experiments as the main statistical method for planning experiments and diagnose the problems of decarburization and hardness in steel wires during heat treatment, but also used multiple regression methods to model statistically the process and Desirability to optimize the process through the appropriate adjustments of the factors.

This study contributes directly to the understanding of the causative agent of loss of carbon steel wire during the heat treatment (phenomenon called decarburization). This carbon loss disqualifies the material for your applications originally envisaged, as with mechanical reduction of the amount of the chemical element carbon steel becomes less resistant to 
traction and less hard what would prevent your use for various applications mechanics. The importance of this study is that knowing the cause of decarburization during heat treatment is possible to neutralize the causative agent so that the problem does not reoccur and that it will be possible to reduce the loss (scrapping) of this material due to occurrence of this phenomenon. However, it is important to note that this study demonstrated the occurrence of this phenomenon only for this specific process, with specific equipment and with the particular steel, so it's not safe to say that this phenomenon that occurred in this study will also be reproduced if any pre-established conditions is changed or if the process to be compared has some characteristic different from conditions experienced in this research.

\section{Literature Review}

\subsection{Decarburization}

The decarburization is a phenomenon that can occur during heat treatment of steels and involves the loss of carbon in the surface of the material. The decarburization is related to the microstructure of the material and, consequently, with its properties. The main consequences of decarburization are the loss of surface hardness, tensile strength, wear resistance and fatigue strength due to the depletion of carbon from the surface, and may disqualify the material for those functions it normally would play. The decarburization is more serious for applications where the material is not subjected to surface treatment, as for example, carburizing.

According to Tschiptschin (1980), the decarburization can occur for a variety of situations, depending on the specific characteristics of the thermal treatment. The loss of carbon from the surface of the material happens as a result of factors such as temperature and treatment time, furnace atmosphere (presence of oxidizing gases such as oxygen, carbon dioxide and water steam), carbon steel alloy elements. It can occur through chemical reactions with hydrogen or material with iron oxides, in this last case, forming the slag which is the top layer of rust. By comparison with standards, you can sort the decarburization in three basic types (HERNANDEZ JR.; FONSECA; DICK, 2010):

1. Type 1: superficial Region with measurable thickness with ferrite and carbides, free under this layer of ferrite, Pearlite fraction increases with the distance from the surface;

2. Type 2: Occurs on the surface a loss exceeding $50 \%$ average value of the carbon content of the steel, but without the complete decarburization of this region; and

3. Type 3: Occurs on the surface a loss less than $50 \%$ of the average carbon content of steel.

Surface Oxidation is made up of three iron oxides (shown in Figure 1), so this factor has been the main factor chosen because there was a chance that the oxidation reaction with the internal temperature of the oven during heat treatment and reduce the carbon from the surface layer of steel wire.

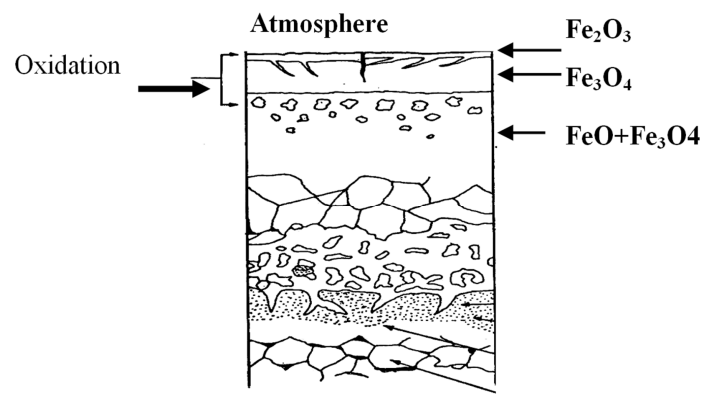

Figure 1. Draw of Oxidation (Tschiptschin, 1980).

According to Callister (2002) and Chiaverini (2012), hardness is a metal resistance measure to penetration. The most common methods to determine a metal hardness are Brinell, Vickers and Rockwell. In this research, only the Brinell method $(\mathrm{BH})$ is used. Brinell hardness values $(\mathrm{BH})$, as shown in Figure 2, are calculated by dividing applied load by penetration area. The diameter penetrator (D) is a hardened steel ball for materials of medium or low hardness, or tungsten carbide for high hardness materials. The test machine has a light microscope which makes the circle diameter measurement ( $\mathrm{d}$, in $\mathrm{mm})$, which corresponds to the spherical cap projection printed on the sample. Brinell hardness $(\mathrm{BH})$ is given by the applied load $(\mathrm{P}$, in $\mathrm{kgf})$ divided by the print area, as shown in equation 1 .

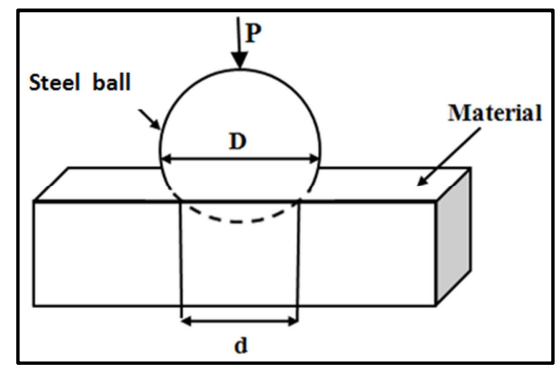

Figure 2. Brinell hardness (BH) method Illustration.

$$
B H=\frac{2 P}{\pi D\left(D-\sqrt{D^{2}}-d^{2}\right)}\left[\mathrm{kgf} / \mathrm{mm}^{2}\right]
$$

\subsection{Design of Experiments}

According to Lima et al. (2011), Silva and Silva (2008) and Granato et al. (2011), the design of experiments (DOE) is very adequate to study several process factors and their interactions complexity in order to solve problems by means of statistical analysis.

The factorial planning is widely used in experiments involving several factors where it is necessary to study the effect of all of them on one or more answers (MONTGOMERY, 2013).

According to Rosa et al. (2009) and Robin et al. (2010) report that among the most appropriate statistical methods for investigation of influential variables there is the method Design of Experiments. This method is used to set the input 
factors and response variables, planning experiments and establish the order of trial in order to obtain results with greater statistical accuracy at the lowest possible cost.

To perform a factorial planning, you must specify the levels at which each factor should be studied and the more important of these special cases is called $2^{\mathrm{k}}$ factorial planning, which uses two-level factors $\mathrm{k}$ each. In this type of experiment, a full replica requires $2 \times 2 \times 2 \times \ldots \ldots 2=2^{\mathrm{k}}$ observations (NETO et al., 2007).

Montgomery and Runger (2003) state that multiple linear regression is used for situations involving more than one regressor, and the models can include interaction effects. An interaction between two variables can be represented by a cross term, for if we assume that $x_{3}=x_{1} x_{2}$ and $\beta_{3=} \beta_{12}$, then the model, including interaction terms, will be as shown in equation 2 .

$$
Y=\beta_{0}+\beta_{1} x_{1}+\beta_{2} x_{2}+\beta_{3} x_{3}+\ldots+\varepsilon
$$

In this expression, $\mathrm{Y}$ is the dependent variable; the independent variables are represented by $x_{1}, x_{2}, \ldots, x_{n}$ and $\varepsilon$ is the random error term. The term "linear" is used because the equation is a linear function of the unknown parameters $\beta_{0}, \beta_{1}$, $\beta_{2}$ and $\beta_{\mathrm{n}}$. In this model, the parameter $\beta_{0}$ is the plane intersection; $\beta_{1}, \beta_{2}$ and $\beta_{\mathrm{n}}$ are the regression partial coefficients.

A mathematical model consists of a set of equations that represent a quantitatively, the assumptions that were used in building the model. Such equations are solved on the basis of some known or provided for in the real world and can be tested by means of comparison with known data (SODRÉ, 2007).

According to Benyounis and Olabi (2008), multiple regression technique when used in addition to the design of experiments, is very efficient to develop statistical models that quantify the influence of process input variables for prediction of output variables and multiple regression is used for situations involving more than one regressor, as (3):

$$
Y=\beta_{0}+\beta_{1} x_{1}+\beta_{2} x_{2}+\ldots+\beta_{n} x_{n}+\mathcal{E}
$$

In this expression $\mathrm{Y}$ represents the dependent variable, independent variables are represented by $x_{1}, x_{2}, \ldots, x_{n}$ and $\varepsilon$ is the random error term. The unknown parameters are $\beta_{0}, \beta_{1}$, $\beta_{2 \mathrm{e}} \beta_{\mathrm{n}}$. In this model, the parameter $\beta_{0}$ is the intersection of the plan, $\beta_{1}, \beta_{2}$ e $\beta_{\mathrm{n}}$ are the partial regression coefficients.

The models that include interaction effects, according to Montgomery and Runger (2003), can be analyzed by multiple regression method. An interaction between two variables can be represented by a term, because if we concede that $x_{3}=x_{1} x_{2}$ and $\beta_{3}=\beta_{12}$, so the model including interaction terms, uses (4):

$$
Y=\beta_{0}+\beta_{1} x_{1}+\beta_{2} x_{2}+\beta_{3} x_{3}+\ldots+\varepsilon
$$

The desirability method is a method used for determining the best conditions for process adjustment, making possible simultaneous optimization of multiple responses. This being so, the best responses conditions are obtained simultaneously minimizing, maximizing or seeking nominal values of specifications, depending on the most convenient situation for the process (WANG, WAN, 2009).

Each one of responses $\left(\mathrm{Y}_{1}, \mathrm{Y}_{2} \ldots \mathrm{Y}_{\mathrm{k}}\right)$ of original set is transformed, such that $d_{i}$ belongs to interval $0 \leq d_{i} \leq 1$. The $d_{i}$ value increases when the $i$ th response approaches the imposed limits. Equation 5 is used to find the D global index, from combination of each one responses processed through a geometric mean.

$$
D=\left(d_{1}\left(Y_{1}\right) \times d_{2}\left(Y_{2}\right) \ldots \times d_{k}\left(Y_{k}\right)\right)^{\frac{1}{k}}
$$

As a result of geometric mean represented by equation 5 , the value $\mathrm{D}$ evaluates, in a general way, the levels of the combined set of responses. It is an index also belonging to interval $[0,1]$ and will be maximized when all responses approach as much as possible of its specifications. The closer of one D is, the closer the original responses will be of their respective specification limits. The general optimal point of system is the optimal point achieved by maximizing the geometric mean, calculated from individual desirability functions. Advantage of using geometric mean is to make the overall solution is achieved in a balanced way, allowing all responses can achieve the expected values and forcing algorithm to approach the imposed specifications (PAIVA, 2008).

According to Derringer and Suich (1980), the algorithm will depend on the optimization type desired for response (maximization, minimization or normalization) of desired limits within the specification and the amounts (weights) of each one response, which identifies the main characteristics of different optimization types, as follows:

1. Minimize Function: The desirability function value increases as the original response value approaches a minimum target value;

2. Normalize Function: When response moves toward the target, the desirability function value increases;

3. Maximize Function: The desirability function value increases when the response value increases.

Paiva (2008) and WU (2005) state that when a response maximization is wished, the transformation formula is shown in equation 6 :

$$
d i=\left\{\begin{array}{cc}
0 & \hat{Y}_{i}<L S L \\
{\left[\frac{\hat{Y_{i}}-L i}{T i-L i}\right]^{R}} & \hat{L}_{i} \leq \hat{Y}_{i} \leq T_{i} \\
1 & \hat{Y}_{i}>T_{i}
\end{array}\right.
$$

Where: $L_{i}, T_{i}$ and $H_{i}$ are, respectively, the values of major, minor and acceptable target for the $i$ th response.

The $\mathrm{R}$ value, in Equation 6, indicates a preponderance of the superior limit (LSL). Values higher than unity should be used when the response (Yi) increases rapidly above $L_{i}$. Therefore, $d_{i}$ increases slowly, while the response value is being maximized. Consequently, to maximize $\mathrm{D}$, the $i$ th response must be much larger than $L_{i}$. One can choose $\mathrm{R}$ 
$<1$, when it is critical to find values for the response below the fixed limits.

In cases where the objective is to reach a target value, the transformation formulation stops being unilateral and becomes bilateral. The bilateral formulation, represented by equation 7, occurs when the interest response has two restrictions: one maximum and the other one minimum.

$$
d_{i}=\left\{\begin{array}{c}
\hat{Y}_{i}<L_{i} \text { ou } \hat{Y}_{i}>H_{i} \\
{\left[\frac{H_{i}-\hat{Y}_{i}}{H i-T i}\right]^{R} \quad T_{i} \leq \hat{Y}_{i} \leq H_{i}} \\
{\left[\frac{\hat{Y}_{i}-L i}{T i-L i}\right]^{R} \quad L_{i} \leq \hat{Y}_{i} \leq T_{i}}
\end{array}\right.
$$

Table 1. Chemical composition of SAE $51 B 35$ steel wire used in the research.

\begin{tabular}{lllllllllll}
\hline $\mathbf{C} \%$ & $\mathbf{N i} \%$ & $\mathbf{S i} \%$ & $\mathbf{M n} \%$ & $\mathbf{P \%}$ & $\mathbf{M o \%}$ & $\mathbf{A l} \%$ & $\mathbf{C u} \%$ & $\mathbf{S \%}$ & $\mathbf{C r} \%$ & $\mathbf{B} \%$ \\
\hline 0.35 & 0.07 & 0.25 & 0.46 & 0.021 & 0.020 & 0.022 & 0.15 & 0.002 & 0.97 & 0.0017 \\
\hline
\end{tabular}

\subsection{Characteristics of Heat Treatment Furnace}

For this study we used a high-convection Bell type oven, with heat treatment capacity for 20 tons of wire per cycle.

The principle of operation of Bell type furnaces boils down basically in the heating and cooling of material loaded at the base, protected by the canopy of protection, with internal pressure always positive. This pressure is obtained by injection of inert protective gas (N2) with flow rate of $200 \mathrm{~m}^{3} / \mathrm{h}$ in the first 90 minutes of purging and $300 \mathrm{~m}^{3} / \mathrm{h}$ after the initial bleed. The goal of maintaining the positive internal

\section{Materials E Methods}

\subsection{Material, Factors Selection and Experimental Organization}

The drawn steel wire is a product widely used in mechanical construction, which is the raw material used for the manufacture of various products such as: screws; chains; bearings and covers for sails.

This product has a great demand of consumers in Brazil and in the world, because they are used in machines in various sectors and especially by the automotive industry.

The material used in this work was the SAE 51B35 steel wire, cold drawn, with $12.85 \mathrm{~mm}$ diameter, round. Chemical analysis was carried out in the chemical laboratory of the company funding the research, using optical emission spectrometer ARL brand. The results are presented in table 1.
Table 2. Characteristics of thermal treatment cycles.

\begin{tabular}{llllll}
\hline \multicolumn{2}{l}{ Cycle X } & & \multicolumn{2}{l}{ Cycle Y } \\
\hline & \multicolumn{2}{l}{ Temperature (Degrees Centigrade) } & \multirow{2}{*}{ Time (Minutes) } & \multicolumn{2}{c}{ Temperature (Degrees Centigrade) } \\
\cline { 2 - 3 } & Start & End & & Start & End \\
\hline 1 & 25 & 760 & 1320 & 25 & 765 \\
\hline
\end{tabular}

\subsection{Selection of Factors, Response Variable and Choice of Array of Design of Experiments}

For the selection of the factors raised the possible causes that could influence the decarburization of the wire, being selected the following:

1. Oxidation, assuming for the sake of argument that iron contained oxides, somehow during the thermal treatment, could react with the surface layer of steel wire by subtracting the carbon.

2. Heat treatment cycle, assuming the time and the temperature had influence on decarburization;

3. Pressure (Dew point), assuming that the amount of oxygen inside the oven had influence on pressure is to prevent the entry of oxygen inside the base (canopy).

According to Hernandez Jr.; Fonseca; Dick (2010) the heat treatment is widely used in medium and high carbon steels in order to produce a structure of globular carbide in a ferritic structure array. This structure provides the reduction of hardness, the increase in ductility and Machinability.

Loads of steel (SAE 51B35) used in this research were treated according to the $\mathrm{X}$ and $\mathrm{Y}$, whose time and temperature settings are represented in table 2 . decarburization. This factor characterized by measuring the internal pressure inside heat treatment furnace. The values indicate measurements performed by the specific equipment of this heat treatment furnace;

4. Moisture, assuming the oxygen emitted by the sample in wet condition, because the moisture caused by the wet material would evaporate after heating and oxygen released could react chemically with the surface layer of steel due to high temperature in the oven;

The selection of the levels of the factors was based on the actual condition of the process (the minimum and maximum for all factors).

Factors such as Oxidation, Heat treatment cycle, Pressure and Moisture were tested by means of the factorial planning, using the matrix $2^{3}$, represented in table 3 . 
Table 3. Factorial Matrix $2^{4}$.

\begin{tabular}{lllll}
\hline Experiments & Oxidation & Heat treatment cycle & Pressure & Moisture \\
\hline 1 & - & - & - & - \\
2 & + & - & - & - \\
3 & - & + & - & - \\
4 & + & + & - & - \\
5 & - & - & + & - \\
6 & + & - & + & - \\
7 & - & + & + & - \\
8 & + & + & + & - \\
9 & - & - & - & + \\
10 & + & - & - & + \\
11 & - & + & - & + \\
12 & + & + & - & + \\
13 & - & - & + & + \\
14 & + & - & + & + \\
15 & - & + & + & + \\
16 & + & + & + & + \\
\hline
\end{tabular}

variables $(\beta)$ were used rather than physical variables (real adjustments) of investigated factors, in order to preserve the confidential data of the company which funds the research. Variables reduction was calculated according to Montgomery and Runger (2003), using the physical value $(\alpha)$ that one wants to test subtracted from the mean $(\mu)$ between the minimum and maximum of factors adjustments. The result was divided by half the amplitude (R) between the minimum and maximum values of factors adjustment. Thus, the reduced variables dimensionality was restricted to the range [-1 to 1], according to equation 8 .

$$
\beta=\frac{\alpha-\mu}{\frac{R}{2}}
$$

For experiments planning accomplishment, reduced

Table 4. Transformation of physical variables to reduced variables.

\begin{tabular}{lll}
\hline Input variables & Values (physical units) Minimum / Maximum & Values (reduced variables) \\
\hline Oxidation & With Oxidation / without Oxidation & $-1 / 1$ \\
Heat treatment cycle & Cycle X / Cycle Y & $-1 / 1$ \\
furnace Pressure & $-35 /-25$ & $-1 / 1$ \\
Moisture & With Moisture / without Moisture & $-1 / 1$ \\
\hline
\end{tabular}

The raw material (SAE 51B35 drawn steel wire) selected for realization of experiments was obtained from the same manufacturing batch to the lower variation possible in relation to the decarburization, since it would hardly be possible to obtain in this case materials exempt from this feature.

The sample was sent to the laboratory of the company funding the research to measure the initial decarburization and to her this analysis an average value of $0,03 \mathrm{~mm}$ deep.

\section{Sequence of Experiments and Statistical Analysis}

In table 5 are the order in which the experiments were executed, its settings and adjustments the experimental results of decarburization and hardship (responses).

Table 5. Adjustments the experimental results of decarburization and Hardness.

\begin{tabular}{|c|c|c|c|c|c|c|}
\hline Std Order & Oxidation & Heat treatment cycle & Furnace pressure & Moisture & Decarburization & Hardness \\
\hline 1 & -1 & -1 & -1 & -1 & 0,18 & 260 \\
\hline 2 & 1 & -1 & -1 & -1 & 0,08 & 290 \\
\hline 3 & -1 & 1 & -1 & -1 & 0,17 & 256 \\
\hline 4 & 1 & 1 & -1 & -1 & 0,07 & 281 \\
\hline 5 & -1 & -1 & 1 & -1 & 0,22 & 270 \\
\hline 6 & 1 & -1 & 1 & -1 & 0,12 & 294 \\
\hline 7 & -1 & 1 & 1 & -1 & 0,23 & 264 \\
\hline 8 & 1 & 1 & 1 & -1 & 0,10 & 290 \\
\hline 9 & -1 & -1 & -1 & 1 & 0,18 & 250 \\
\hline 10 & 1 & -1 & -1 & 1 & 0,09 & 280 \\
\hline 11 & -1 & 1 & -1 & 1 & 0,17 & 258 \\
\hline 12 & 1 & 1 & -1 & 1 & 0,08 & 281 \\
\hline 13 & -1 & -1 & 1 & 1 & 0,213 & 254 \\
\hline 14 & 1 & -1 & 1 & 1 & 0,09 & 293 \\
\hline 15 & -1 & 1 & 1 & 1 & 0,23 & 258 \\
\hline 16 & 1 & 1 & 1 & 1 & 0,10 & 290 \\
\hline
\end{tabular}

Factors significance was tested at a $90 \%$ confidence level $(\mathrm{p}<0.10)$. This analysis was carried out separately so that factors significance for Decarburization (response) and could be verified, as shown in Table 5. 
Table 5. Significance test for Decarburization, by means of the Minitab Statistical Software.

\begin{tabular}{llll}
\hline Terms & Effect & Coefficient & P-value \\
\hline Constant & & $\mathbf{0 . 1 4 5 1 9}$ & $\mathbf{0 . 0 0 6}$ \\
\hline (A: Oxidation) & -0.10787 & -0.05394 & 0.017 \\
(B: Heat treatment cycle) & -0.00287 & 0.500 \\
(C: Furnace pressure) & 0.03537 & 0.052 \\
(D: Moisture) & -0.00213 & 0.595 \\
(A)(B) & -0.00463 & 0.01769 & 0.354 \\
(A) (C) & -0.01288 & -0.00106 & 0.140 \\
(A) (D) & -0.00038 & -0.00231 & 0.917 \\
(B) (C) & 0.00712 & -0.00644 & 0.244 \\
(B) (D) & 0.00462 & -0.00019 & 0.354 \\
(C) (D) & -0.00712 & 0.00356 & 0.244 \\
(A) (B) (C) & -0.00462 & 0.00231 & \\
(A) (B) (D) & 0.00288 & -0.00356 & \\
(A) (C) (D) & -0.00537 & -0.00231 & \\
(B) (C) (D) & 0.00463 & 0.00144 & 0.500 \\
\hline
\end{tabular}

It was verified through analysis of table 5 and Figure 3 , using $90 \%$ confidence, that the influential factors on decarburization are oxidation and furnace pressure. No interaction proved influential.

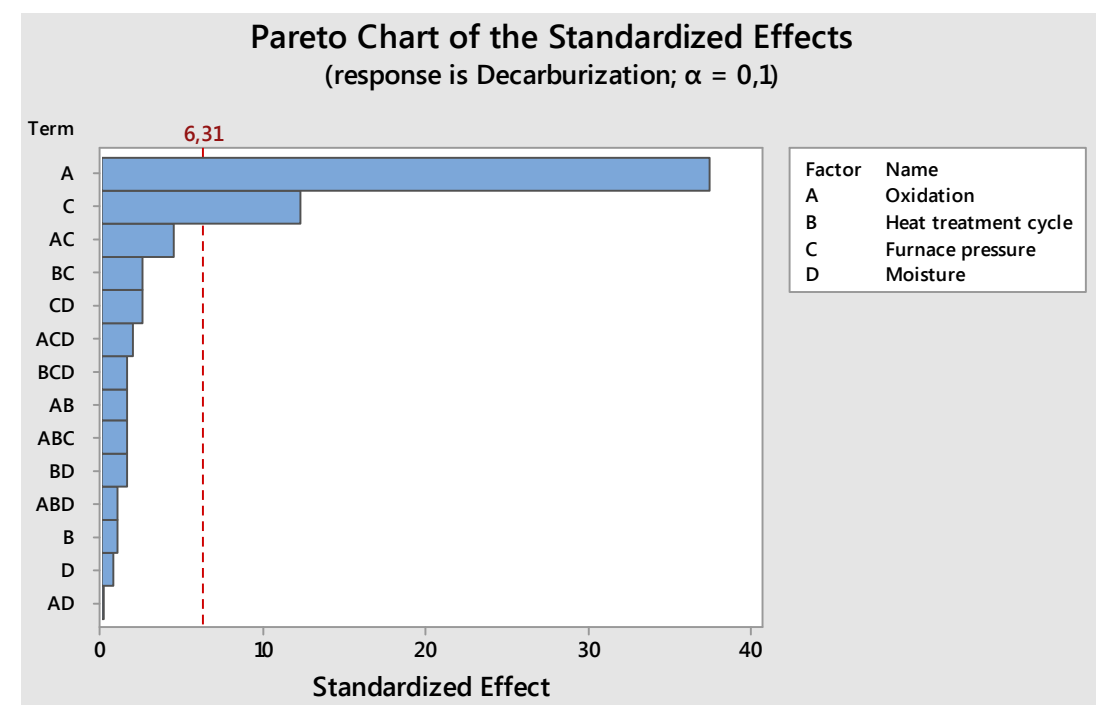

Figure 3. Pareto Chart of the Decarburization.

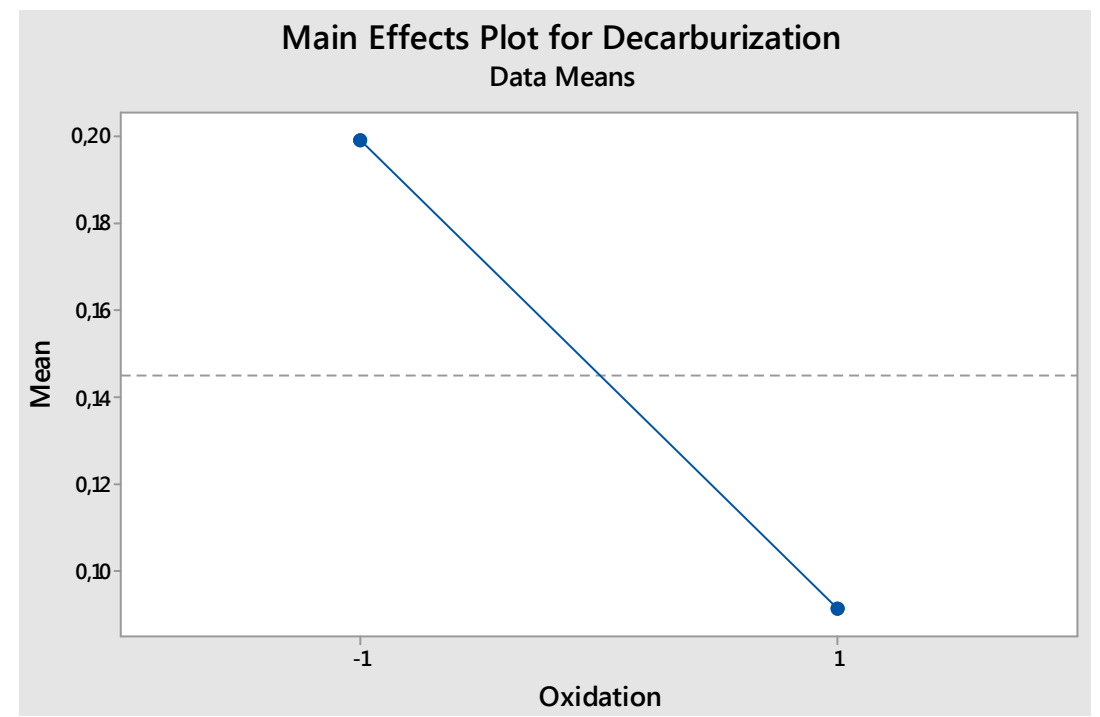

Figure 4. Oxidation factor effect on decarburization. 


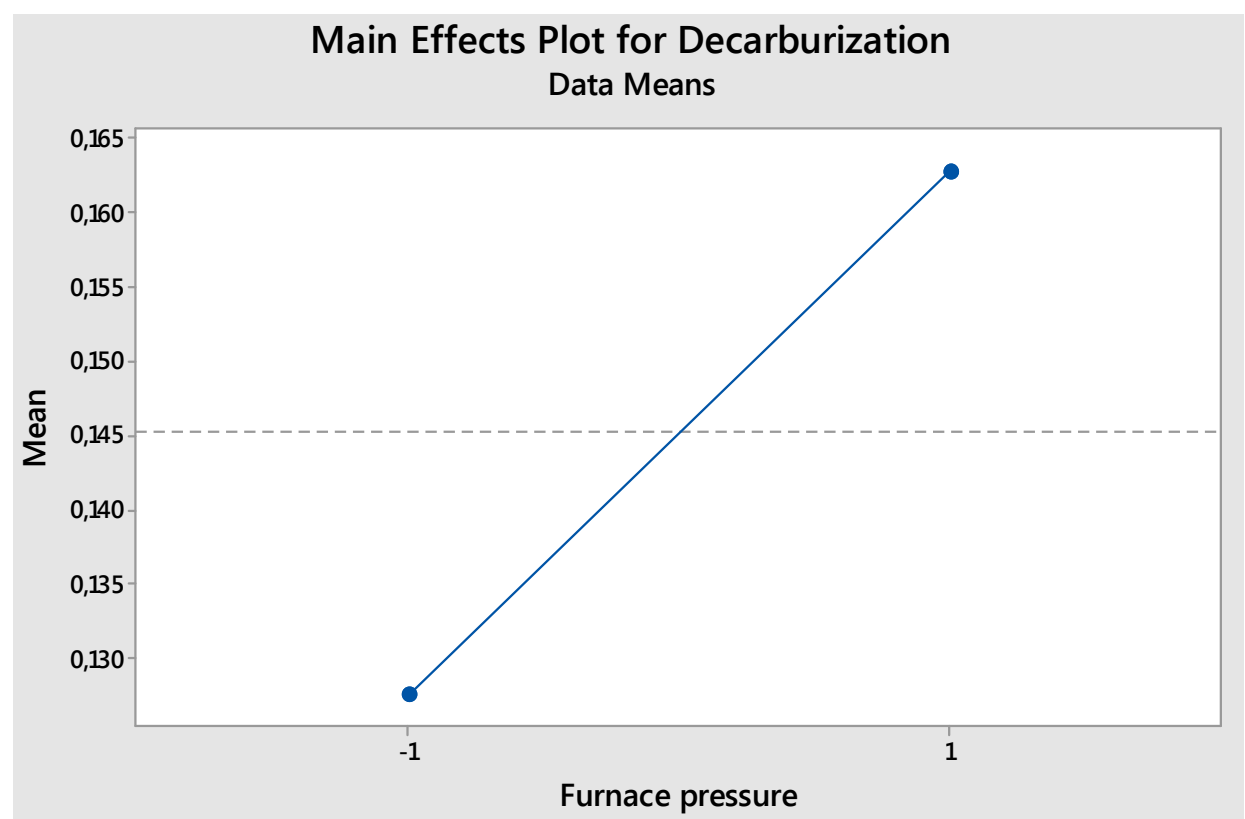

Figure 5. Furnace pressure factor effect on decarburization.

As shown in Figure 4 you can see that the decarburization increases when the oxidation is present (adjust -1), because the oxidation causes a chemical reaction with the temperature of the heat treatment which takes the subtraction of the surface of carbon steel, causing the carbon depletion in the surface of the material. It is also possible to finish analyzing the Figure 5 that the decarburization increases when the Furnace pressure is -25 (adjust 1) because as the pressure is achieved by injecting nitrogen gas in the oven in order to expel the oxygen before heat treatment, this pressure adjustment indicates a lower nitrogen flow which could mean a greater likelihood of left some residue of oxygen inside the oven and is known in the literature that the oxygen in contact with the heat treatment temperature can cause decarburization in steel. Therefore, it was done in this study with the lowest pressure $(-25)$ is the largest due to possibility of decarburization remaining residue of oxygen during heat treatment.

Considering only the influential factors to the construction of the mathematical model for decarburization (as shown in Table 5), the model will be (9):

$$
\text { Decarburization }=0,14519-0,05394 \text { (oxidation) }+0,01769 \text { (furnace pressure) }
$$

Factors significance was tested at a $90 \%$ confidence level $(\mathrm{p}<0.10)$. This analysis was carried out separately so that factors significance for Hardness (response) and could be verified, as shown in Table 6.

Table 6. Statistical analysis and Significance test for Hardness, by means of the Minitab Statistical Software.

\begin{tabular}{llll}
\hline Terms & Effect & Coefficient & P-value \\
\hline Constant & & $\mathbf{2 7 3 . 0 6 3}$ & $\mathbf{0 . 0 0 1}$ \\
\hline (A: Oxidation) & 28.625 & 14.312 & 0.019 \\
(B: Heat treatment cycle) & -1.625 & -0.813 & 0.314 \\
(C: Furnace pressure) & 7.125 & 3.563 & 0.078 \\
(D: Moisture) & -5.125 & -2.562 & 0.108 \\
(A)(B) & -2.125 & -1.062 & 0.249 \\
(A) (C) & 1.625 & 0.314 \\
(A) (D) & 2,375 & 0.813 & 0.225 \\
(B) (C) & -0.625 & 1.188 & 0.605 \\
(B) (D) & 4.125 & -0.313 & \\
(C) (D) & -0.625 & 2.063 & 0.605 \\
(A) (B) (C) & 0.875 & -0.313 & 0.500 \\
(A) (B) (D) & -1.375 & 0.437 & 0.361 \\
(A) (C) (D) & 2.875 & -0.687 & 0.188 \\
(B) (C) (D) & -1.375 & 1.438 & 0.361 \\
\hline
\end{tabular}

It was verified through analysis of table 6 and Figure 6 , using $90 \%$ confidence, that the influential factors on Hardness are oxidation and furnace pressure. No interaction proved influential. 


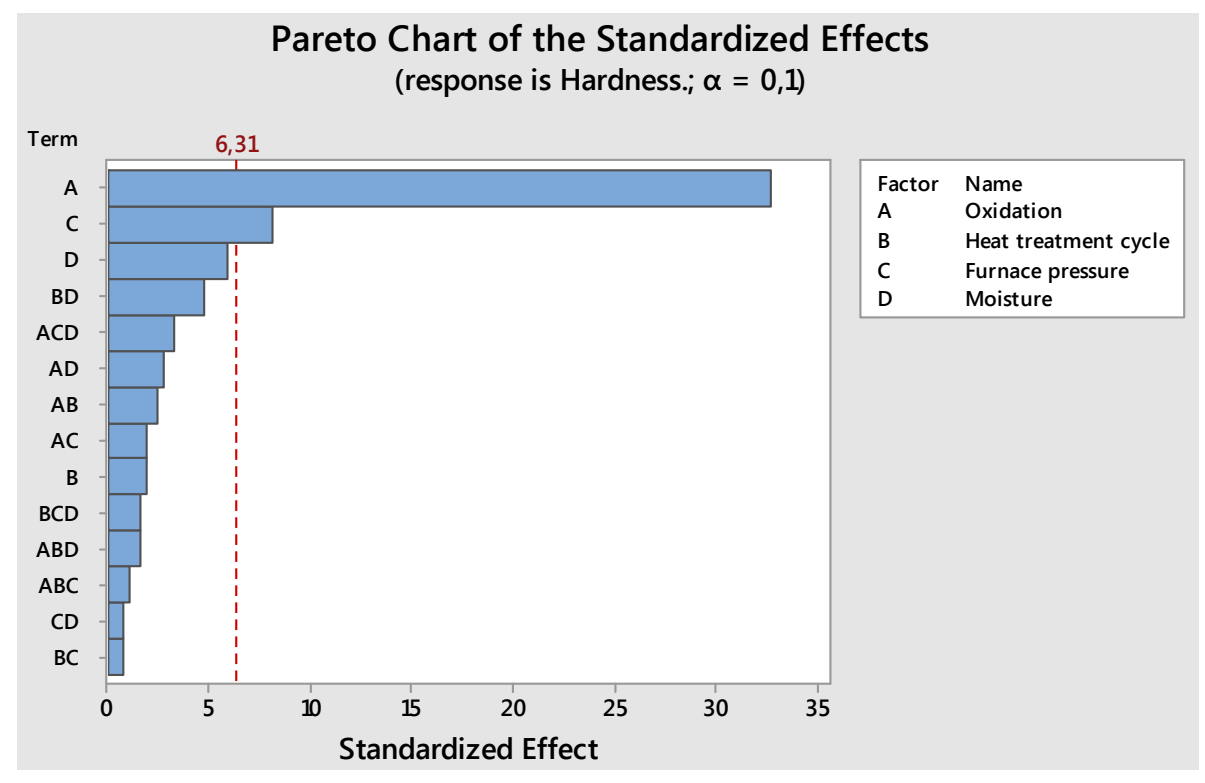

Figure 6. Pareto Chart of the Hardness.

As shown in Figure 7 you can see that the Hardness decreases when the oxidation is present (adjust -1), because the oxidation causes subtraction of the carbon on surface steel, causing the reduction of hardness, because the hardness is directly related to the amount of the chemical element carbon.

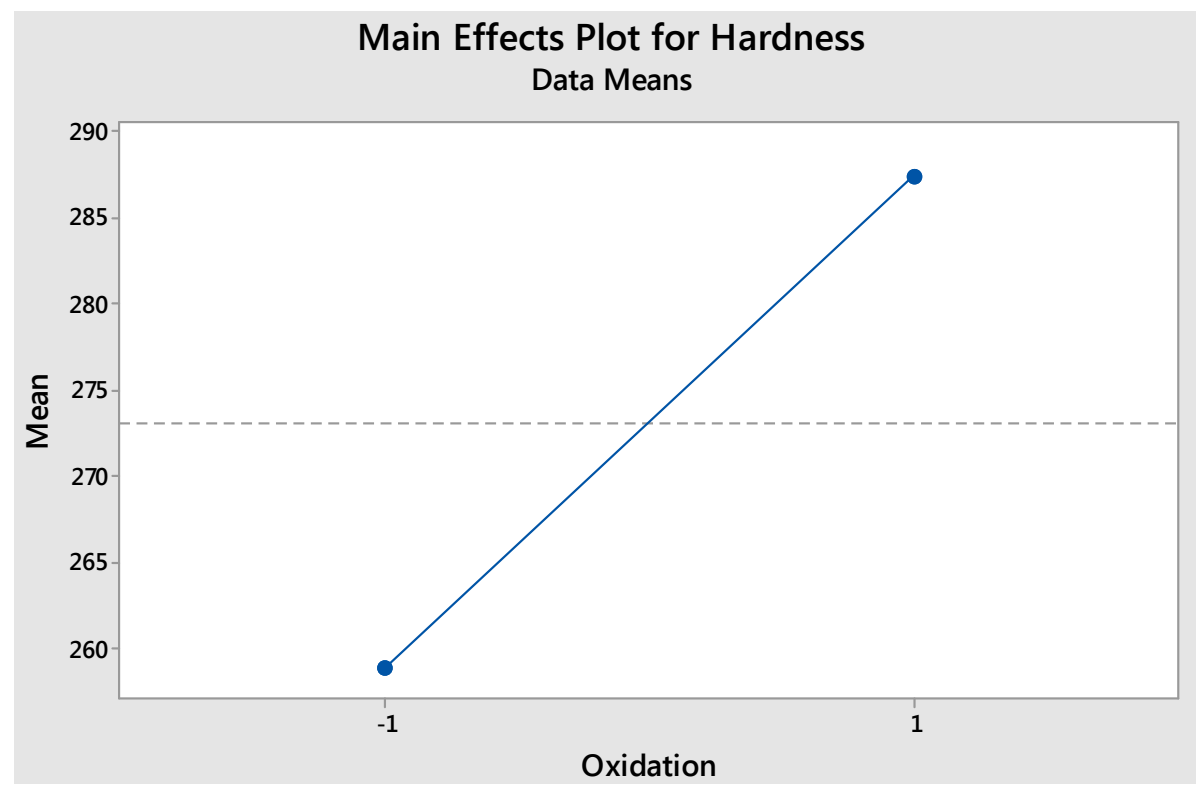

Figure 7. Oxidation factor effect on Hardness.

Considering only the influential factors to the construction of the mathematical model for Hardness (as shown in Table 6), the model will be (10):

Hardness $=273,063-14,330$ (oxidation) $+3,562$ (furnace pressure)

\section{Application of desirability Function for Optimization}

For process optimization by means of desirability function, firstly, it was necessary to formulate the specifications required for the decarburization and hardness. For decarburization what you want is that there is no the decarburization, so the smaller the decarburization is better for the process. In relation to the desired hardness is the material get the harshest possible.

The composite desirability (D) is the overall index calculated from combination of each response variables processed through a geometric mean and this index is responsible for showing the best condition to optimize all responses variables at the same time. To obtain the highest 
possible value for $\mathrm{D}$, which reflects in the best condition of response variables in relation to their specifications care (displayed in Figure 8), the best adjustments using factors reduced variables [-1 to 1$]$ are:

a) Oxidation, adjusted in 1.0 ;

b) Furnace pressure, adjusted in 1.0.

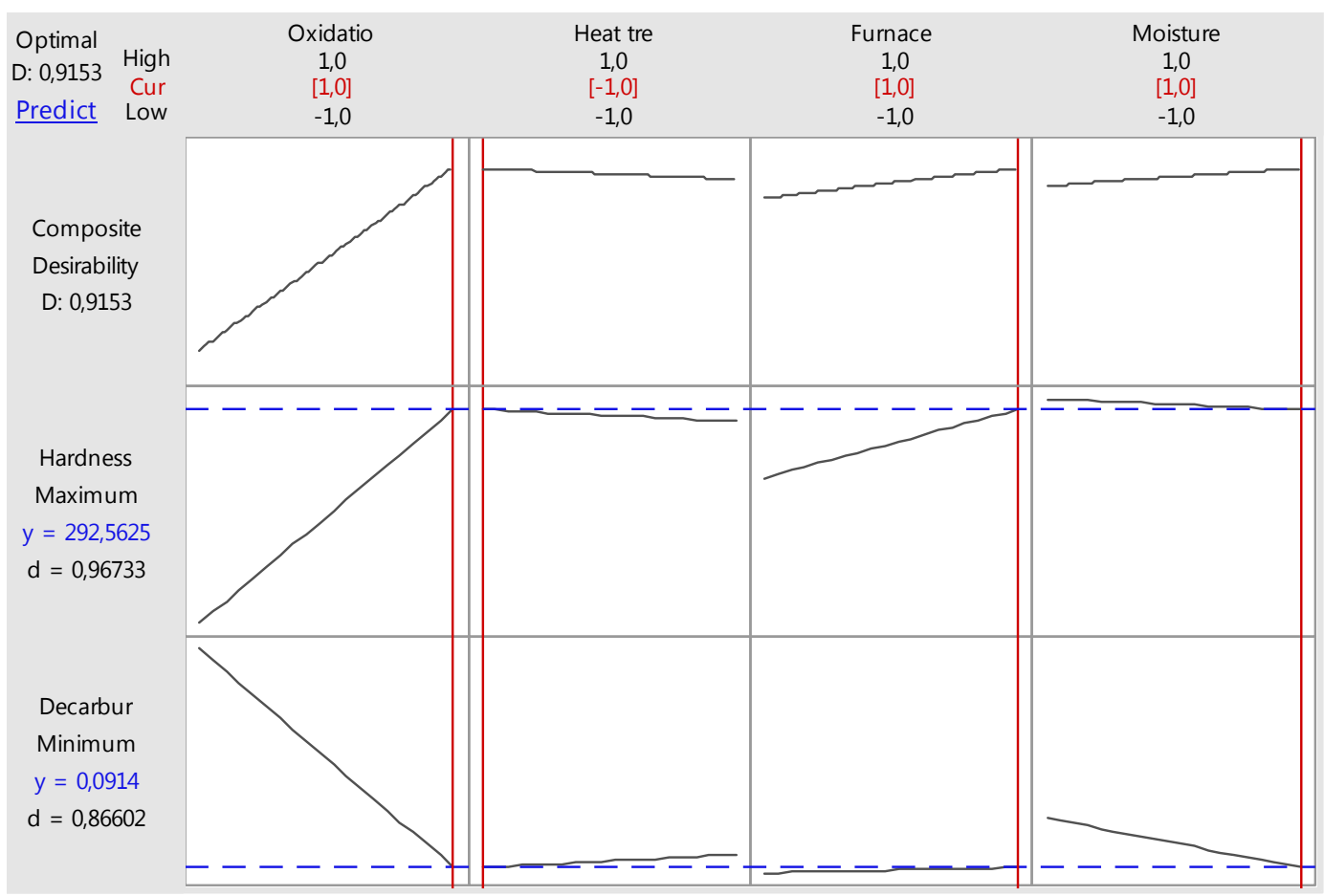

Figure 8. Desirability function applied in multiple responses (Minitab Statistical Software).

Looking at Figure 8, it can be seen that $\mathrm{D}$ value belonging to [0-1] interval, is maximized when all responses are close to their specifications, for the closer D is of 1, the closer the original responses will be of their respective specification. The optimal general point of the system is the optimum point achieved by geometric mean maximization calculated from individual desirability functions (d), which in this case are values for each one of response variables given below:

1. For response variable called hardness, $d=0.96733$;

2. For response variable called decarburization, $\mathrm{d}=0.86602$.

Values obtained for desirability (D) and individual desirability (d), show that the process was well optimized, since these indices are found to be very close to the optimum condition (0.9153). Thus, it was possible to find that values obtained for this optimized condition are in accordance with required specifications and are:

1. For hardness $(y=292.5625 \mathrm{BH})$;

2. For decarburization $(\mathrm{y}=0.0914 \mathrm{~mm})$.

\section{Conclusion}

It was concluded that the oxidation factor and furnace pressure are the factors that cause the decarburization and hardness reduction of drawn steel wire SAE 51B35 during the heat treatment process.

It was concluded that the decarburization increases when the oxidation is present (adjust -1), because the oxidation causes a chemical reaction with the temperature of the heat treatment which takes the subtraction of the surface of carbon steel, causing the carbon depletion in the surface of the material. It is also possible to observe that the decarburization increases when the Furnace pressure is -25 because as the pressure is achieved by injecting nitrogen gas in the oven in order to expel the oxygen before heat treatment, this pressure adjustment indicates a lower nitrogen flow which could mean a greater likelihood of left some residue of oxygen inside the oven and is known in the literature that the oxygen in contact with the heat treatment temperature can cause decarburization in steel. Therefore, it was done in this study with the lowest pressure $(-25)$ is the largest due to possibility of decarburization remaining residue of oxygen during heat treatment.

It was possible to observe also that the Hardness decreases when the oxidation is present, because the oxidation causes subtraction of the carbon on surface steel, causing the reduction of hardness, because the hardness is directly related to the amount of the chemical element carbon.

Through the use of the method Desirability was found the best tweaks of the influential factors to obtain the best condition were processing Oxidation (in 1.0) and Furnace pressure (in 1.0), which amounts in practice to use the material with the total absence of oxidation and the furnace pressure -35 (the that represents the total absence of oxygen inside the furnace).

This conclusion indicated the need to better plan the operational practice of this process, causing the steel wires are previously sandblasted with steel shot or chemically 
pickled for removal of surface oxidation before heat treatment.

There was also the possibility of reduction of decarburization depth by more than $50 \%$ during the heat treatment. However, it is necessary to standardize the oxidation removal before the material be treated thermally. In addition, it is important whenever possible keep the material stored in appropriate locations and protected against the action of rain, thus preventing this is material with moisture (wet) and be placed in the oven to heat treatment in this condition, as this reduced enough the decarburization caused during heat treatment.

It is important to note that the decarburization above 0.11 $\mathrm{mm}$ for steel wire results in your disqualification for their mechanical applications required. Therefore, very important to standardize the removal of oxidation of the surface layer of the wire where the wire is subjected to heat treatment.

\section{References}

[1] BENYOUNIS, K. Y.; OLABI, A. G. Optimization of different welding processes using statistical and numerical approaches - A reference guide, Science Direct, v. 39, p. 483-496, 2008.

[2] CALLISTER JR, W. D. An introduction to materials science and engineering, $5^{\text {a }}$ Edition, Publisher LTC, 2002, p. 589.

[3] CHIAVERINI, V. Steels and cast irons. 7. Edition. São Paulo: Brazilian Association of Metallurgy and materials, 2012. 600 p.

[4] DERRINGER, G., SUICH, R. Simultaneous Optimization of Several Response Variables, Journal of Quality Technology, v 12, n 4, p. 214-219, 1980.

[5] GRANATO, D.; BRANCO, G. F.; CALAdO, V. M. A. Experimental design and application of response surface methodology for process modelling and optimization. A review, Food Research International, Melbourne, v. 1, n. 1, p. $0-14$, oct 2011.

[6] HERNANDEZ JR, P. C.; FONSECA, J. E. F.; DICK, L. F. P. Development of a methodology for evaluation of steels. Part 1: determination of the degree of decarburization, Metallurgy and materials technology; v. 6, n. 3, p. 153-157, jan.- March. 2010 .
[7] LIMA, V. B. S.; BALESTRASSI, P. P.; PAIVA, A. P. Performance optimization of broadband radio frequency amplifiers: an experimental approach, Production, v. 21, n. 1, p. 118-131, jan/march, 2011.

[8] MONTGOMERY, D. C.; RUNGER, G. C. Applied statistics and probability for engineers, $2^{\mathrm{a}}$ Edition, Publisher LTC, 2003, 230-320 p.

[9] MONTGOMERY, C. D. Design and analysis of experiments. 8. ed. New York: John Wiley \& Sons, 2013. 203p.

[10] NETO, B. B.; SCARMINIO, I. S.; BRUNS, R. E. How to make experiments: research and development in science and industry, $3^{\mathrm{a}}$ Edition, Publisher Unicamp, 2007, 480 p.

[11] PAIVA, E. J. Manufacturing optimization with multiple Responses based on capacity indexes, Thesis, Federal University of Itajubá, 2008, 117 p.

[12] ROBIN; A.; ROSA, J. L., SILVA, M. B. Electrodeposition and characterization of $\mathrm{Cu}-\mathrm{Nb}$ composite coatings. Surface \& Coatings Technology, Sidney, v. 205, n. 1, p. 2152-2159, oct 2010.

[13] ROSA, J. L.; ROBIN, A.; SILVA, M. B.; BALDAN, C. A.; PERES, M. P. Electrodeposition of copper on titanium wires: Taguchi experimental design approach. Journal of Materials Processing Technology, Sydney, v. 209, n. 1, p. 1181-1188, jan 2009.

[14] SILVA, H. A.; SILVA, M. B. Application of design of experiments (DOE) in the tube welding zircaloy-4; Production \& Engineering, v. 1, n. 1, p. 41-52, set./dec. 2008.

[15] SODRÉ, M. On the communicational episteme. Arrays USP, São Paulo, v. 1, n. 1, p. 15-26, oct 2007.

[16] TSCHIPTSCHIN, A. P. Introduction to metallographic analysis, Aços Villares, 1980, p. 10-15.

[17] WANG, J.; WAN, W. Application of desirability function based on neural network for optimizing biohydrogen production process, international journal of hydrogen energy, v. 34, p. 1253-1259, 2009.

[18] WU, F. C. optimization of correlated multiple quality characteristics using desirability function. Quality engineering, $v 17, \mathrm{n} 1$, pp. 119-126, 2005. 